\title{
Optimization of energy sources structure to minimize environment pollution
}

\author{
Olga Edeleva $^{1^{*}}$, Valery Stennikov ${ }^{1}$ \\ ${ }^{1}$ Melentiev Energy Systems Institute of Siberian Branch of Russian Academy of Sciences, Irkutsk, Russia
}

\begin{abstract}
The paper gives a general statement of the problem of choosing the structure of energy sources of urban heat supply systems to meet technical, economic and environmental constraints. One of the effective approaches to solve such a problem is the construction and optimization of redundant schemes of technological structures of energy sources. A model based on the theory of energy hubs is presented as one of the methods for constructing the redundant scheme. The application of the theory of energy hubs for selecting the types of energy sources allows, in an enlarged form, selecting the main equipment of energy sources, and evaluating technical and economic indices, and the degree of negative impact on the environment (at the level of gross emissions of harmful substances into the atmosphere). A case study of modeling a redundant system for selecting the optimal structure of energy sources, considering the minimum atmospheric pollution, is illustrated.
\end{abstract}

\section{Introduction}

A significant adverse impact of energy facilities on the environment is the pollution of atmosphere. In Russia, power plants and boiler houses burn about 390 million tons of fuel equivalent a year, throwing into the atmosphere about 3.67 million tons of pollutants, which is $21 \%$ of the total volume (17.35 million tons) of atmospheric emissions for all stationary sources of the Russian Federation as of 2016 [1, 2].

One of the key mechanisms of environmental protection in our country is the assessment of the caused damage and the corresponding payment for emissions of air pollutants. However, as practice shows, the existing algorithm for calculating damage from environmental pollution [3] leads to inadequate compensation for the damage. The operating costs of existing plants for complex chemical purification reach $10 \%$ of the company's annual income, and relative size of penalties is $0.05 \%$. As a result, domestic polluting enterprises do not have effective economic incentives to implement environmental protection measures. To change the situation, it is necessary to clarify the concept of environmental damage, as well as penalties for it. It is important that effective measures for the prevention of harmful emissions

*Corresponding author

E-mail: edel@isem.irk.ru, sva@isem.irk.ru

are justified and taken into account already in the design stage.

An analysis of the domestic scientific and methodological literature, as well as the available methodological tools for the influence of heat supply systems on air pollution, allows us to draw a number of conclusions. The proposed approaches to solve the problems of reconstruction and development of heat supply systems are mainly focused on improving their reliability, controllability and economy. Normally, in these approaches, the activities aimed at reducing the negative impact on the environment are determined for already selected options of the system development, which is not always the best solution [4-8]. The greatest effect on reducing emissions can be achieved when the measures are considered for all compared options [9].

The search for the most profitable composition of energy sources in the urban heat supply systems is a complex problem of scheme-and-structure optimization. Under energy source structure optimization we understand the optimal choice of its type, location and configuration of equipment. The problem has a nonlinear character and is difficult to formalize for practical implementation. The objective is to determine the energy source types, location and configuration of its equipment, including a variety of technical and economic conditions, environmental and territorial restrictions. Solution to such a problem depends on a large number of external and internal factors, such as compliance with the heat and electricity balance conditions; reliability, environmental and other constraints. The environmental constraints that stand out in terms of the degree of impact are the requirements of reducing harmful emissions of pollutants into the atmosphere. Heat power industry is one of the industries that most negatively affect the surface layers of the atmosphere.

A methodological approach based on the construction of redundant schemes, developed both in Russia and other countries, proved rather effective in the optimization of structure of energy sources in urban heat supply systems [10, 
11].

The methodological approach to the construction of redundant schemes is also developed at Melentiev Energy Systems Institute SB RAS. It implies that a researcher constructs a redundant design calculated scheme of a heat supply system as a set of all admissible configurations of the heat network and the location of heat sources, considering constraints related to obstacles on the terrain and sites chosen for placement of the sources [12]. The idea of the approach is that when choosing the heat sources, the redundant scheme is supplemented by a fictitious node and a subset of fictitious links connecting it with those nodes where the optimal heat power of a source is selected. The number of fictitious links for each source node depends on how many alternatives of source types are considered at a given node. The local optimization of various trees of initial approximation is carried out by the directional enumeration of trees. This allows obtaining solutions close to optimal ones. The redundant scheme when prepared includes all possible alternatives, which eliminates the risk of excluding an optimal solution from consideration.

The authors of $[13,14]$ propose such an approach to construct a structural scheme of an energy source based on a redundant scheme. According to this approach, various options of energy source equipment are considered in a single scheme, which contains a finite number of components with their possible interrelationships.

\section{The mathematical statement of the problem}

The mathematical statement of the problem of selecting the structure of energy sources of urban heat supply systems considering technical, economic and environmental constraints can be presented as follows. A set of urban sources $I$ consists of subsets of existing $I_{1}$ and new $I_{2}$ energy sources. For each energy source $i \in I$, set $M_{i}$ is formed. Each component $m$ of this source describes an option of reconstruction and/or modernization of an existing energy source or installation of a new energy source.

The objective function is the sum of costs determined by the composition, type and performance of the system components, USD:

$$
\begin{aligned}
& \mathrm{S}=\sum_{i}^{I} s_{i} \cdot Q_{i}-S_{\text {out }}^{e p s} \cdot W_{\text {out }}^{e p s}+S_{\text {in }}^{e p s} \cdot W_{\text {in }}^{e p s}+ \\
& +\sum_{k}^{K} S_{k} \cdot F_{i k} \Rightarrow \min
\end{aligned}
$$

In this case, the following constraints are met: Urban heat balance, Gcal/year:

$$
\sum_{i}^{I} Q_{i}=\mathrm{Q}^{\mathrm{city}},
$$

urban electricity balance, MWh/year:

$$
\sum_{i}^{I} W_{i}-W^{\text {city }}-W_{\text {out }}^{\mathrm{eps}}+W_{\text {in }}^{\mathrm{eps}}=0 .
$$

The condition for competition in options for the reconstruction and/or modernization of existing energy source $i \in I_{1}$ is as follows:

$$
\sum_{m}^{M_{i}} V_{i}^{m}=1,
$$

the competition condition in the options for each new energy source $i \in I_{2}$ is:

$$
\sum_{m}^{M_{i}} V_{i}^{m}=G_{i},
$$

where $V_{i}^{m}$ determines the implementation / nonimplementation of an option of equipment $m \in M_{i}$ of an energy source $i$ that has a certain set of technical and economic characteristics.

Heat generation by the $i$-th energy source, Gcal:

$$
Q_{i}=\sum_{m}^{M_{i}} Q_{i}^{\mathrm{m}} \cdot V_{i}^{m},
$$

power generation by source $i$, MWh:

$$
W_{i}=\sum_{m}^{M_{i}} W_{i}^{m} \cdot V_{i}^{m},
$$

dependence of heat output on the fuel type:

$$
Q_{i}^{m}=f\left(B_{i}^{m, h}, \ldots, B_{i}^{m+1, h+1}\right),
$$

dependence of electricity output on heat output:

$$
N_{i}^{m}=f\left(Q_{i}^{m}\right),
$$

dependence of electricity output on installed capacity:

$$
W_{i}^{m}=f\left(N_{i}^{m}\right),
$$

dependence of gross emissions of harmful substance $k$ on the fuel type:

$$
F_{i k}^{m}=f\left(B_{i}^{m, h}, \ldots, B_{i}^{m+1, h+1}\right),
$$

constraints on the amount of fuel used:

$$
B_{i}^{m, h} \leq B_{i, \max }^{m, h},
$$

gross emissions of harmful substance $k$ from the $i$-th energy source, $t$ /year: 


$$
F_{i k}=\sum_{m}^{M_{i}} F_{i k}^{m} \cdot V_{i}^{m}
$$

urban heat supply system should meet the standards of the protection of the atmosphere:

- the maximum permissible emissions (MPE) of harmful substances, t/year:

$$
F_{i k} \leq F_{i k}^{\max },
$$

- the maximum permissible concentrations (MPC) for the dispersion of these emissions, $\mathrm{mg} / \mathrm{m}^{3}$ :

$$
\begin{gathered}
C_{k p}-\Delta C_{k p} \leq C_{k}^{\max }, \\
\sum_{i}^{I} \sum_{m}^{M_{i}}\left(C_{k p i}^{m} \cdot V_{i m}\right)=C_{k p}, \\
C_{k p i}^{m}=f\left(F_{i k}^{m}\right) .
\end{gathered}
$$

where $i$ is energy source from set $I ; h$ is type of burned fuel; $m$ is the number of option by type and configuration of the energy source equipment; $Q^{\text {city }}$ is urban heat consumption, Gcal/year; $W^{\text {city }}$ is urban electricity consumption, $\mathrm{MWh} / \mathrm{year} ; \mathrm{W}^{\text {eps }}$ is the need for electricity in the electric power system, which can be covered by electricity from CHP, MWh/year; $B_{i}^{m, h}$ is consumption of fuel type $h$, it is burned by source $i$ when option $m$ is implemented, $B_{i}^{m, h}, \ldots, B_{i}^{m+1, h+1}, \quad \mathrm{t} /$ year; $\quad B_{\max }^{m, h}$ is the maximum possible volume of burned fuel, t/year; $W_{i}$ is electricity supply from source $i, \mathrm{MWh} /$ year; $Q_{i}$ is heat generated by source $i$, Gcal/year; $Q_{i}^{m}$ is heat generated by source $i$ when option $\boldsymbol{m}$ is implemented, Gcal/year; $W_{i}^{m}$ is electricity generated by source $i$ when option $m$ is implemented, MWh/year; $N_{i}^{m}$ is electric power of source $i$ when option $m$ is implemented, MW/year; $V_{i}^{m}$ is implementation of option $m$ of reconstruction and/or expansion and/or modernization of source $i$ or installation of new source $i$; $G_{i}$ is an auxiliary variable of Boolean type, if new source is not installed, then $G_{i}=0$, if it is installed, then $G_{i}=1$. $G_{i}$ depends on $V_{i}^{m}$, for example, if $V_{i}^{m}=1$, $G_{i}$ becomes automatically $G_{i}=1 ; F_{i k}$ is gross emission of harmful substance $k$ of source $i, \mathrm{t} /$ year; $F_{i k}^{\max }$ is the MPE of harmful substance $k$ into the atmosphere, established by calculation for source $i, \mathrm{t} / \mathrm{year} ; C_{k}^{\max }$ is the maximum concentration of substance $\mathrm{k}$ in the atmosphere in the territory under consideration, which is relatively safe for the human and the environment (usually the MPC values established in legislation are taken as a sanitary and hygienic standard), $\mathrm{mg} / \mathrm{m}^{3} ; C_{k p}$ is the calculated concentration of harmful substance $k$ in the atmosphere at point $p, \mathrm{mg} / \mathrm{m}^{3}$; $p$ is the point from set $P_{k}$ of points of the territorial dispersion of harmful substance $k$; $C_{k p i}^{m}$ is concentration resulting from implementation of option $m$ for source $i$, $\mathrm{mg} / \mathrm{m}^{3} ; \Delta C_{k p}$ is a change as a result of implementation of option $m$ for source $i, \mathrm{mg} / \mathrm{m}^{3} ; S$ is costs of urban heat supply system, USD; $s_{i}$ is unit cost at source $i$, USD/Gcal (USD/kW); $W_{\text {in }}^{e p s}$ is volume of electricity purchased from electric power system, MWh/year; $W_{\text {out }}^{\text {eps }}$ is volume of electricity sold to the power system, MWh/year; $S_{i n}^{e l}$ is tariff for purchase of electricity from electric power system, $\mathrm{USD} / \mathrm{kWh} ; S_{\text {out }}^{\text {el }}$ is tariff for sale of electricity to power system, USD/kWh; $S_{k}$ is penalty for exceeding MPE of substance $k$, USD/t.

Figure 1 presents a graphical interpretation of a variety of options for the structure of energy sources of urban heat supply system in the form of a redundant scheme.

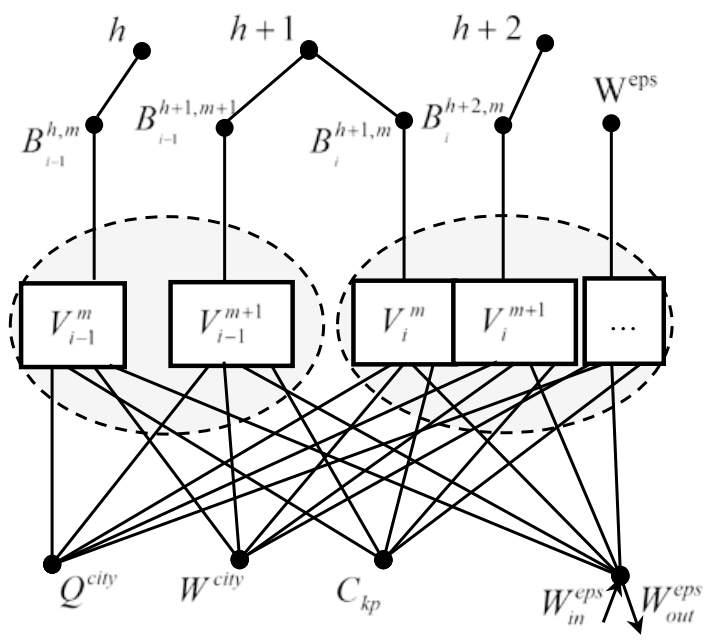

Fig. 1. Redundant scheme of a structure of energy sources of the urban heat supply system.

Rectangles $V_{i}^{m}$ indicate the implementation/nonimplementation of $m$ options of equipment of energy source $i$. The lines going from them to point $Q^{\text {city }}$ are the graphical reflection of heat balance equation (2), lines going to $W^{\text {city }}$ and $W^{\text {eps }}$ correspond to electricity balance equation (3), and the lines directed to point $C_{k p}$ show the concentration of harmful substance at point $p$ in terms of substance $k$.

Dotted lines in Figure 1 show possible competing options 
for each energy source.

The above mathematical formulation is a mixed integer nonlinear programming (MINLP) problem. It is nonlinear, which in particular is explained by the presence of integer variables $V_{i}^{m}$, and nonlinear dependences (8)-(11).

Therefore, to solve it, we propose decomposing it into simpler subproblems that are solved in stages. In the first stage, subproblem (1)-(14) is solved, where the types of energy sources are determined, the composition of the main equipment is selected, and the negative impact on the environment is assessed (at the level of gross emissions).

In the subsequent stages, equations (15)-(17) are taken into account, that is, for the energy sources chosen in the first stage, the equipment is determined, given the MPC of harmful substances in the surface layer of the atmosphere.

\section{Modelling of redundant scheme of energy source structure}

Optimization of a structure of energy sources as the first stage problem can be solved using the theory of energy hubs [15], which is widely used in modern practice [16].

The energy hub is an intermediate link between energy producers and the transport infrastructure, on the one hand, and consumers, on the other. It ensures the transfer, conversion, production and storage of various types of energy carriers. The energy hub transforms the energy carrier, changing its potential, which allows integrating any consumer into the system.

The technological model of the hub includes four structural components [17]:

1. Input flows of energy carriers supplied directly from producers or from the system of energy transport infrastructure (fuel supply systems, from renewable energy sources (wind and solar energy), for example, electricity from centralized electricity supply system or heat from district heating system, etc.

2. Energy converters ensure the conversion of some types of energy carriers into their other types (boiler room, chiller, heat pump, etc.), or responsible for a change in physical parameters of energy carriers (electrical transformer, network pump, pressure regulator, etc.).

3. Energy storage (accumulator, battery) designed to store fuel, energy accumulation (for example, heat accumulator, power storage, gas tank, coal storage, etc.).

4. Output flows of energy carriers sent to consumers loads (heat, cooling, power consumption, etc.).

The energy carriers in the energy hub can be transferred from the input to the output with changing parameters (for example, electric voltage) or with a significant transformation changing the form of the energy carrier (for example, the cogeneration unit can convert gas into electricity and heat).

The modeling of hubs is based on three assumptions [18]:

1 . There are no losses in the hubs, except for conversion and storage losses;

2. The simulated system is in a stable, steady state;

3. The energy flow is always directed from input to outputs of the hub.

The main idea of applying the energy hub methodology is to model the structure of option $m \in M_{i}$ of energy source $i$ in the form of an energy hub whose existence is determined by variable $V_{i}^{m}$. General structure of the energy source, shown in Figure 2, consists only of energy converters, since energy storage components are not provided in the energy source structure. Figure 2 shows converters $R_{\gamma}$, inputs $P_{\alpha}$ and outputs $L_{\beta}$, where $1 \leq \gamma \leq z, 1 \leq \alpha \leq \omega, 1 \leq \beta \leq \mu$ ,$Z$ is the number of converters, $\omega$ is the number of inputs, $\mu$ is the number of outputs. The energy flows going through converters $R_{\gamma}$ can be described in a vector form:

$$
\mathbf{L}=\mathbf{C} \cdot \mathbf{P},
$$

where $\mathbf{L}$ - the vector of outputs, i.e. energy supply (heat and electricity production), harmful emissions, etc.; $\mathbf{P}$ - vector of inputs, i.e. consumption of primary energy (fuel, electricity); $\mathbf{C}$ - input-to-output coupling matrix.

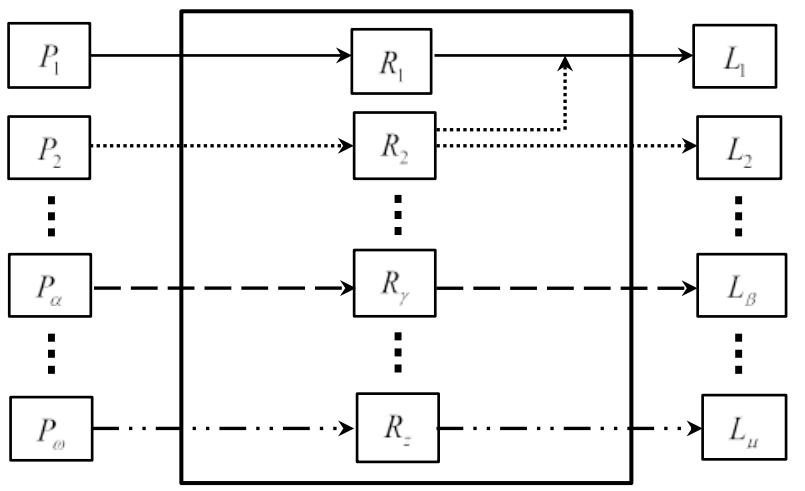

Fig. 2. Representation of the energy source structure in the form of an energy hub.

Matrix C describes mapping of the input flows of converters to the output flows. Components $\mathbf{C}$ are the coupling coefficients of converters $C_{\alpha \beta}$, each connecting one input $P_{\alpha}$ with output $L_{\beta}$ :

$$
L_{\beta}=c_{\alpha \beta} \cdot P_{\alpha},
$$

where $\alpha, \beta$ are the input and output energy carriers, respectively.

The coupling coefficient $C_{\alpha \beta}$ of converters characterizes the efficiency of conversion of fuel $\alpha$ into energy $\beta$ and depends on the fuel type (coal, gas, etc.), equipment types and capacities (boiler, turbine, etc.) and its operating conditions.

If $P_{\alpha}$ is common for several converters, then $C_{\alpha \beta}$ will also depend on the distribution of the input energy flows, which is described by the distribution coefficients $v_{\alpha}^{\gamma}$. Each of the coefficients determines the proportion of input flow $P_{\alpha}$ coming to converter $\gamma$ : 


$$
P_{\alpha}^{\gamma}=v_{\alpha}^{\gamma} \cdot P_{\alpha}
$$

The following conditions are imposed on the distribution of energy carriers between converters in the energy source structure:

$$
\begin{gathered}
0 \leq v_{\alpha}^{\gamma} \leq 1 \forall \alpha, \forall \gamma, \\
\sum_{r} v_{\alpha}^{\gamma}=1 \forall \alpha .
\end{gathered}
$$

The outputs of the energy source structure, in addition to energy flows, can be the amounts of harmful emissions produced by the combustion of organic fuels (for example, $\mathrm{SO}_{x}, \mathrm{NO}_{x}, \mathrm{~V}_{2} \mathrm{O}_{5}, \mathrm{CO}$, ash, benzopyrene, etc.). Then the corresponding coefficients $C_{\alpha \beta}$ will be the specific emissions of substance $\beta$ during combustion of energy carrier $\alpha$.

Let us consider, for example, an option of an energy source to be designed. Its scheme is shown in Figure 3. The structure of the energy source includes three converters: an electrical transformer, a gas turbine and a gas boiler.

The transformer is characterized by efficiency $C_{e e}^{T}$. The gas turbine is characterized by electrical and heat efficiency $C_{g e}^{G T}$ and $C_{g h}^{G T}$, respectively. The efficiency of the gas boiler is denoted by $c_{g h}^{b o}$. Gross $N O$ emissions depend on fuel consumption through coupling coefficients $C_{g N O}^{G T}$ and $C_{g N O}^{b o}$.

According to (18), the relation between its inputs and outputs is described by equation:

$$
\left[\begin{array}{lll}
L_{e} & L_{h} & L_{N O}
\end{array}\right]^{T}=\mathbf{C} \cdot\left[\begin{array}{ll}
P_{e} & P_{g}
\end{array}\right]^{T},
$$

where $\mathbf{C}$ is input-to-output coupling matrix; converters $L_{e}$, $L_{h}, L_{N O}$ are output flows of electricity, heat and $N O$ emissions, respectively; $P_{e}, P_{g}$ are input electricity and gas flows, respectively.

Matrix $\mathbf{C}$ of the energy source whose model is demonstrated in Figure 3 is written in the following form:

$$
\mathbf{C}=\left[\begin{array}{cc}
c_{e e}^{T} & v_{g e}^{G T} \\
0 & v_{g}^{G T} c_{g h}^{G T}+v_{g}^{b o} c_{g h}^{b o} \\
0 & v_{g}^{G T} c_{g N O}^{G T}+c_{g N O}^{b o}
\end{array}\right],
$$

where, $v_{g}^{G T}, v_{g}^{b o}$ are the distribution coefficients of gas for the gas turbine and the gas boiler, respectively. According to (21)-(22), the following conditions should be met:

$$
0 \leq v_{g}^{G T} \leq 1
$$

$$
0 \leq v_{g}^{b o} \leq 1
$$

$$
v_{g}^{G T}+v_{g}^{b o}=1
$$

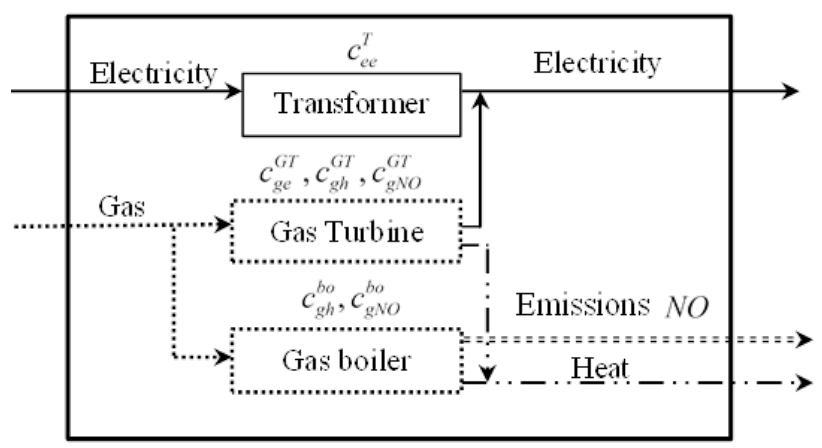

Fig. 3. Scheme of possible energy source alternative.

Summarizing the aforesaid, based on the theory of energy hubs, dependences (8)-(11) describing the operation of energy source $i$ in option $m \in M_{i}$ can be written in form of (18) with additional constraints:

$$
\begin{gathered}
\underline{P}_{\alpha}^{\gamma} \leq v_{\alpha}^{\gamma} \cdot P_{\alpha} \leq \overline{P_{\alpha}^{\gamma}}, \\
\underline{L}_{\beta} \leq L_{\beta} \leq \overline{L_{\beta}},
\end{gathered}
$$

where, $\underline{P}_{\alpha}^{\gamma}, \overline{P_{\alpha}^{\gamma}}$ are the minimum and maximum flows of energy carries $\alpha$ in converter $\gamma$, respectively; $\underline{L}_{\beta}$ and $\overline{L_{\beta}}$ are the minimum and maximum output flow of energy carriers $\beta$, respectively.

Expression (18) describes the processes of converting fuel into energy. The parameters $Q_{i}^{m}, N_{i}^{m}, W_{i}^{m}, F_{i k}^{m}$ are the components $\mathbf{L}, B_{i}^{m, h}$ that are included in composition $\mathbf{P}$.

To simplify the modeling of transformation processes, the authors of [19] propose using a piecewise linear approximation of the efficiency functions of converters and dependencies of pollutant emissions on fuel consumption.

Expression (28) represents technical capabilities of the converters (their minimum and maximum load) [19].

Expression (29) imposes a constraint on the output flows. In the case that the environmental factor should be considered, it will characterize the MPE of harmful substances in the atmosphere.

Thus, the considered options of energy source structures in the form of energy hubs form a redundant scheme (Figure 1) [20].

\section{Case study of selecting an optimal structure of energy source}

The construction of a redundant scheme of an energy source begins with selection of options for the equipment configuration. The optimal structure choice the is made for a redundant set of 
single energy source equipment, that has an industrial heat load Table 2. Sizes of penalty for negative impact on the environment, of $1.32 \mathrm{Gcal} / \mathrm{h}$. Technical, economic and cost indices for the options of energy source equipment are given in Table 1.

Table 1. Plant options for one energy source

\begin{tabular}{|c|c|c|c|}
\hline Parameter name & \multicolumn{3}{|c|}{ Value } \\
\hline $\begin{array}{c}\text { Option number } \\
\text { (source structure) }\end{array}$ & 1 & 2 & 3 \\
\hline Plant type & $\begin{array}{c}\text { E-1/9- } \\
1 \mathrm{M}\end{array}$ & $\begin{array}{c}3516 \text { HR } \\
\text { SITA54 }\end{array}$ & $\begin{array}{c}\text { DG98M } \\
\text { KUV-30 }\end{array}$ \\
\hline Number of plants & 3 & 2 & 2 \\
\hline Fuel type & fuel oil & gas & gas \\
\hline $\begin{array}{c}\text { Consumption of fuel } \\
\text { by one plant, kgce/h }\end{array}$ & 81.4 & 464.7 & 471.2 \\
\hline $\begin{array}{c}\text { Annual costs of fuel } \\
\text { purchase by one } \\
\text { plant, thousand } \\
\text { USD/year }\end{array}$ & 152.28 & 124.84 & 125.68 \\
\hline $\begin{array}{c}\text { Heat capacity of one } \\
\text { plant, Gcal/h }\end{array}$ & 1.965 & 1.64 & 1.34 \\
\hline $\begin{array}{c}\text { Electrical capacity of } \\
\text { one plant, MW }\end{array}$ & - & 1.03 & 1 \\
\hline $\begin{array}{c}\text { Electricity purchase, } \\
\text { MW }\end{array}$ & 2 & - & - \\
\hline $\begin{array}{c}\text { Annual costs of } \\
\text { electricity purchase, } \\
\text { thousand USD/year }\end{array}$ & 1051.2 & - & - \\
\hline $\begin{array}{c}\text { The cost of a set of } \\
\text { plants, thousand USD }\end{array}$ & 20.1 & 11 & 12 \\
\hline $\begin{array}{c}\text { The cost of laying a } \\
\text { gas pipeline, } \\
\text { thousand USD }\end{array}$ & - & 9 & 9 \\
\hline \multicolumn{1}{|c|}{ - } & & \\
\hline
\end{tabular}

Option 1 suggests the installation of oil fuel-fired boilers E-1/9-1M. Option 2 suggests the installation of a Mini-CHP based on low-power gas-fired plants SITA54 manufactured in France. Option 3 includes a Mini-CHP based on gas plants DG98M with a low-power gas-fired waste heat boiler KUV30. All the options have equal heat and electricity output. To this end, when the energy source equipment does not produce electricity, it is purchased from an external electric power system (Table 1, Option 1).

Figure 4 demonstrates the gross emissions of harmful substances by energy source option.

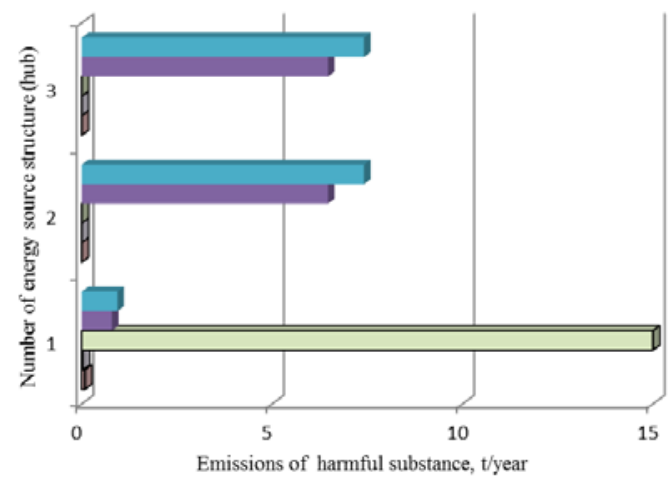

$=\mathrm{CO}$

- NOx

asox

口V2O5

口Ash

Fig. 4. Gross emissions of harmful substances by option of energy source.

Table 2 indicates the sizes of penalties for harmful substance emission, taken according to [21].
2018

\begin{tabular}{|c|c|}
\hline Name of harmful substance & Thousand USD/t \\
\hline Nitrogen dioxide, $\mathrm{NO}_{\mathrm{x}}$ & 0.0021 \\
\hline Benzopyrene & 84.19 \\
\hline Vanadium Pentadoxide, $\mathrm{V}_{2} \mathrm{O}_{5}$ & 0.042 \\
\hline Ash & 0.034 \\
\hline Sulfur dioxide, $\mathrm{SO}_{\mathrm{x}}$ & 0.00069 \\
\hline Carbon oxide, $\mathrm{CO}$ & 0.000025 \\
\hline
\end{tabular}

Figure 5 shows the models of power plants in the form of hubs created according to the options of equipment presented in Table 1.

The outputs of hubs, in addition to heat and electricity are the annual emissions of harmful substances.

Comparison of the considered options of the energy source structure in terms of technical and economic indices, as well as emissions of harmful substances into the atmosphere with the help of the method proposed above, made it possible to obtain the optimal solution, which corresponds to option 2 (Figure 5, hub 2).

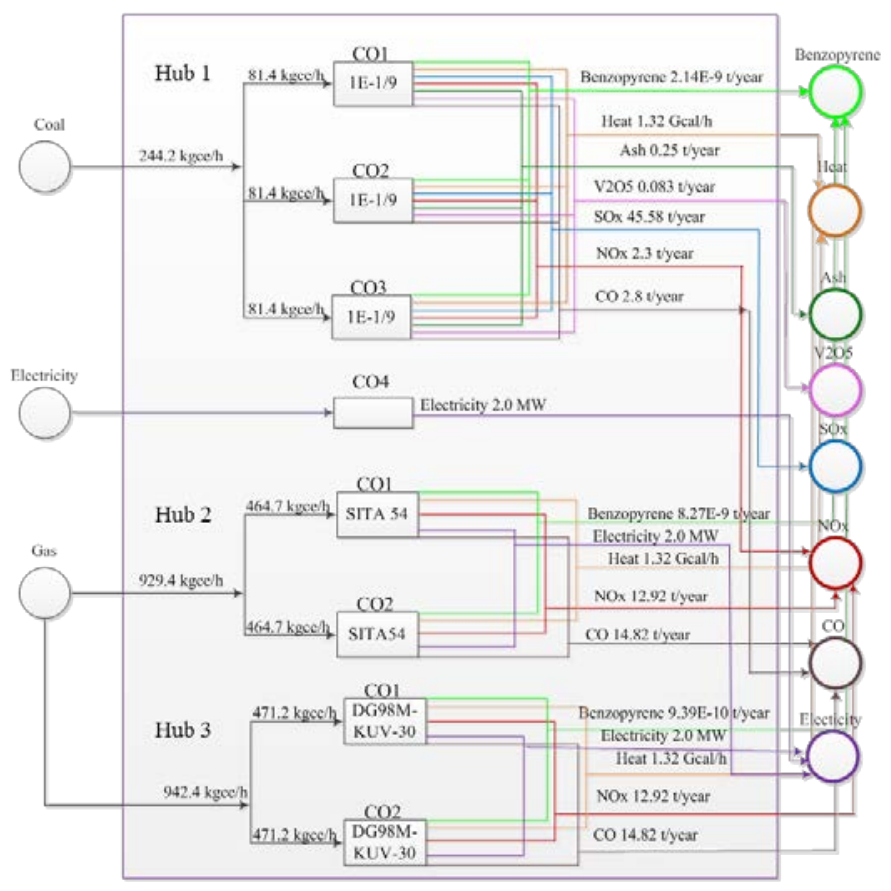

Fig. 5. Options of energy source equipment.

This option of the structure suggests installing a natural gas fired Mini CHP of type 3512HR SITA54 with a heat capacity of $1.64 \mathrm{Gcal} / \mathrm{h}$ and a maximum electric power providing the needs of an industrial enterprise of 2.06 MW. The gross emissions of harmful substances when operating at the design heat load in this option of the energy source structure are minimal and will be: $\mathrm{NO}_{\mathrm{x}}-12.92 \mathrm{t} /$ year, CO $-14.82 \mathrm{t} /$ year, benzopyrene $-8.27 \mathrm{E}-9$ t/year.

\section{Conclusions}

The choice of the energy sources optimal structure is a complex nonlinear problem due to the presence of discrete variables, non-linear functions, for example, power 
generation, dependence of pollutant emissions on fuel consumption, etc. We propose solving this problem in stages. In the first stage, the types of energy sources are determined, the composition of the main equipment is selected, the negative impact of energy sources on the environment is assessed (at the level of gross emissions). In the second stage, for the selected areas of energy sources development, the equipment composition is specified considering the MPC of harmful substances in the surface layer of the atmosphere.

The problem of the first stage can be solved by constructing redundant schemes of energy source structures by the methodology of energy hubs. This provides the following advantages:

- the flexibility of the model as a result of considering more connections and types of equipment for energy supply to consumers;

- the opportunity to optimize the types of power plants, the cost of generated energy, levels of environmental pollution and tackle other problems by selecting different combinations of input vectors;

- the relative ease to take into account environmental constraints, because gross emissions of harmful substances as well as technological indices are considered as output parameters.

The considered case study demonstrates that, in the first stage of optimizing the energy sources structure, the equipment characteristics can be linearized, which allows solving the problem of choosing the directions of energy sources development as a linear programming problem with integer variables.

The research was carried out within the project III.17.4.1 (no. AAAA-A17-117030310432-9) of the Fundamental Research Program of the Siberian Branch of the Russian Academy of Sciences.

\section{References}

1. Form of federal statistical observation no. 4-TER "Information on the use of fuel and energy resources for 2016”. URL: http://www.gks.ru.

2. State report on the state and protection of the environment of the Russian Federation in 2016, Moscow, Russian Federation: Ministry of Natural Resources of Russia; NIANature (2017)

3. Law of the Russian Federation "On Environmental Protection" of 10.01.2002 no. 7-FZ, 97 p. URL: https://fzrf.su/zakon/ob-ohrane-okruzhayushchej-sredy-7-fz/.

4. E.V. Sennova, V.G. Sidler, Mathematical modeling and optimization of developing heat supply systems (Novosibirsk, Russian Federation: Nauka, 1987).

5. L.S. Khrilyov, I.A. Smirnov, Optimization of heating systems and centralized heat supply (Moscow, Russian Federation: Energia, 1978).

6. LS. Popyrin, K.S. Svetlov, G.M. Belyaev, and others Research of heat supply systems (Moscow, Russian Federation: Nauka, 1989).

7. A.I. Yufa, D.R. Nosulko, Complex optimization of heat supply (Kiev, Ukraine: Tekhnika, 1988).

8. A.V. Fedyaev, O.N. Fedyaeva, Complex problems of development of heat supply systems (Novosibirsk, Russian
Federation: Nauka, 2000).

9. A.M. Bronstein, V.A. Litvin, I.I. Rusin, Ecologization of the economy: methods of regional management (Moscow, Russian Federation: Nauka, 1990).

10. N.N. Merenkova, E.V. Sennova, V.A. Stennikov "Scheme-structural optimization of centralized heat supply systems”, Electronic Modeling, no. 6, pp. 76-82, 1982. (in Russian)

11. S. Mitra, L Sun., I.E. Grossmann, "Optimal schedul-ing of in-dustrial combined heat and power plants un-der timesensitive electricity prices”, Energy, 54, 194-211 (2013).

12. E.V. Sennova, V.G. Sidler, Mathematical modeling and optimization of developing heat-supply systems (Novosibirsk, Russian Federation: Science, 1987).

13. H. L. Lam, "Extended P-graph applications in supply chain and process network synthesis", Current Opinion in Chemical Engineering, 2(4), 475-486 (2013).

14. F. Friedler, K. Tarjan, Y. W. Huang, L. T.Fan, "Graphtheoretic approach to process synthesis: axioms and theorems”, Chemical Engineering Science, 47(8), 1973-1988 (1992).

15. M. Giedl, G. Andersson, "Optimal Coupling of Energy Infrastructures”, Power Tech, IEEE Lausanne, 1398-1403 (2007).

16. M. Mohammadi, Y. Noorollahi, B. Mohammadi-ivatloo, H. Yousefi, "Energy hub: From a model to a concept", A review. Renewable and Sustainable Energy Reviews, 80, 1512-1527 (2017).

17. M. Almassalkhi, I. Hiskens "Optimization framework for the analysis of large scale networks of energy hubs", 17th Power System Computation (Conf. Stockholm, Sweden, 2011).

18. M. Geidl, and G. Andersson, "Operational and structural optimization of multi-carrier energy systems”, International Transactions on Electrical Energy Systems, 16(5), 463-477 (2006).

19. M.R. Almassalkhi, A. Towle "Enabling city-scale multienergy optimal dispatch with energy hubs" (In Power Systems Computation Conference (PSCC), 2016).

20. A. Maroufmashat, S.Sattari, R.Roshandel, M. Fowler, and A. Elkamel "Multi-objective optimization for design and operation of distributed energy systems through the multienergy hub network approach”, Industrial \& Engineering Chemistry Research, 55(33), 8950-8966 (2016).

21. On the rates of payment for the negative impact on the environment and additional coefficients. Decree of the Government of the Russian Federation of 09.12.2017 no. 1499. URL: http://rulaws.ru/goverment/postanovleniepravitelstva-rf-ot-13.09.2016-n-913. 